\title{
PISA SYNDROME INDUCED BY RAPID INCREASE AND HIGH DOSAGE OF RISPERIDONE
}

\author{
Quirino Cordeiro', Stevin Zung ${ }^{2}$, Homero Vallada ${ }^{3}$
}

Pisa syndrome (PS) is a rare condition of acute or tardive dystonia characterized by a body involuntary sustained lateral flexion with the head to one side, creating a "leaning tower" posture. The essential symptoms for the diagnosis of PS are the presence of persistent dystonia of the trunk, and lateral flexion with mildly backward axial rotation of the trunk, the absence of other dystonic regions of the body, a history of medication preceding or concurrent with the onset of dystonia, the absence of known reasons for secondary dystonia, and a negative family history for dystonia'. The referential items supporting the diagnosis of the syndrome are worsening of the posture abnormality in walking, indifference to posture abnormality without agony (anosognosia), and improvement in the abnormality of the posture by withdrawal of the causal agents'. Different from other side effects related to antipsychotic treatment ${ }^{2}$, there are putative risk factors described for PS, including previous prolonged treatment with typical antipsychotics, combined pharmacological treatment, female gender, old age, presence of an

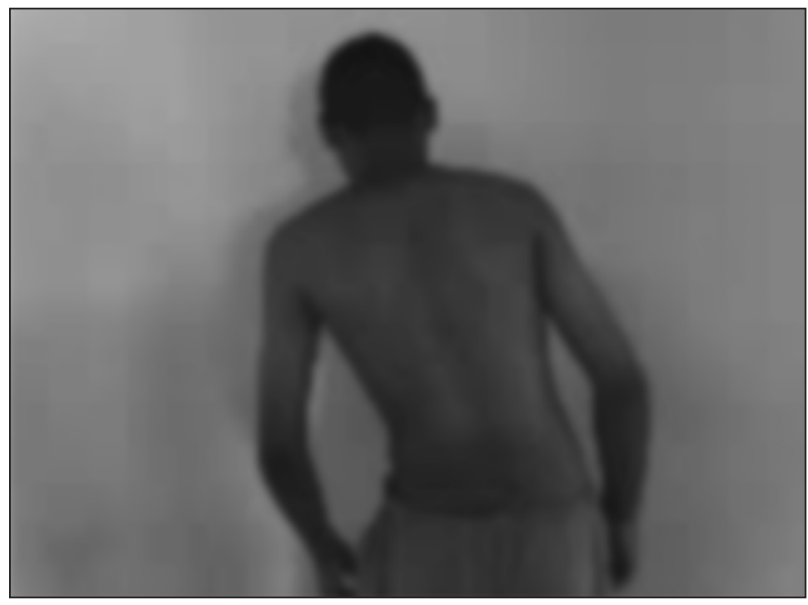

Figure. Patient presenting tonic flexion of trunk and head toward the left along with a slight backward axial rotation. organic brain disorder ${ }^{3}$. Most of PS cases have been described as adverse effects of prolonged exposure to conventional antipsychotics, however more recently, other drugs, including atypical antipsychotics, have been implicated in the pathophysiology of $\mathrm{PS}^{4}$.

We describe the case of a patient with no classical risk factors for PS, who developed the disorder induced by rapid increase and high dosage of risperidone.

\section{CASE}

An 18-year-old man was admitted to our inpatient unit because of a severe psychotic exacerbation. Since the diagnosis of DSM-IV hebephrenic schizophrenia, two years ago, he had been treated with risperidone, a maximum of $4 \mathrm{mg} /$ day, presenting a good clinical control. However two months before the admission, the patient discontinued his medication and began to present thought and behavioral disorganization, delusions, auditive hallucinations, agitation, insomnia.

In the beginning of the admission, he was administered risperidone $4 \mathrm{mg} /$ day and diazepam $30 \mathrm{mg} /$ day for one month. As the clinical features were not improving with such medication, the dosage of risperidone was increased until $6 \mathrm{mg} /$ day and diazepam was switched to clonazepam $6 \mathrm{mg} /$ day with the aim to control the episodes of agitation and insomnia. After three weeks with such medication, risperidone was increased to $12 \mathrm{mg}$ /day because of the inadequate control of the psychotic symptoms. One week after risperidone augmentation, an acute dystonic reaction (tonic flexion of trunk and head toward the left along with a slight backward axial rotation) was observed (Figure). Risperidone was immediately discontinued and an adjunctive treatment with biperiden, an anticholinergic drug, was initiated. Biperiden was introduced in a dosage of $6 \mathrm{mg} /$ day by oral administration. In addition, in the period of three days that followed the beginning of PS the patient has received $20 \mathrm{mg}$ of biperiden by intramuscular administration. PS completely disappeared within 3 days after risperidone discontinuation and complementary anticholinergic therapy. After that, risperidone

\footnotetext{
SÍNDROME DE PISA INDUZIDA POR AUMENTO RÁPIDO E DOSAGEM ELEVADA DE RISPERIDONA

'Doutor em Ciências pelo Departamento de Psiquiatria da Faculdade de Medicina da Universidade de São Paulo, São Paulo SP, Brazil (FMUSP), Pesquisador do Instituto de Psiquiatria do Hospital das Clínicas da FMUSP; ${ }^{2}$ Mestre e Doutor em Ciências pelo Departamento de Psiquiatria da FMUSP, Pesquisador do Instituto de Psiquiatria do Hospital das Clínicas da FMUSP, Diretor Clínico do Hospital João Evangelista; ${ }^{3}$ Professor Associado do Departamento de Psiquiatria da FMUSP.
} 
was switched to olanzapine, until a dosage of $10 \mathrm{mg} /$ day, with a good antipsychotic response.

On admission, the physical examination revealed non-focal neurological deficits. No evidence of other extrapyramidal symptoms was found. The patient had no personal history of drug abuse, no history of head trauma or other neurological problems, and no family history of dystonia or other movement disorders. Secondary dystonias resulting from metabolic disorder, organic disorder, or infection were ruled out.

\section{DISCUSSION}

A dysfunction of cerebral dopaminergic pathways, which are strategic in the regulation of axial muscle tone, has been related as a possible central factor in PS pathophysiology ${ }^{5}$. Risperidone is a selective monoaminergic antagonist with a high affinity for dopaminergic $D_{2}$ receptors. Blockade of $D_{2}$ receptors by classical antipsychotics ameliorate the positive symptoms of schizophrenia. However, this blockade is considered responsible for the occurrence of extrapyramidal symptoms. At therapeutic dosages, risperidone's combined serotonin and dopamine antagonism is supposed to be responsible for its effectiveness on positive and possibly negative symptoms of schizophrenia and its lack of extrapyramidal side effects at dosages lower than $6 \mathrm{mg} /$ day. The reported incidence of acute dystonia with risperidone is greater than placebo at high dosages (16 mg/day), however no greater than placebo in dosages lower than $6 \mathrm{mg} /$ day $^{6}$. In clinical populations, risperidone has been associated with dosage-dependent induction of extrapyramidal adverse effects occurring in the upper dosage range $(>6 \mathrm{mg} / \text { day })^{6,7}$. Therefore, high dosages of risperidone may be associated with extrapyramidal side effects, such as dystonia ${ }^{7}$. In the present report, such phenomenon may be happened, as the patient has received a high dosage of risperidone (12 $\mathrm{mg} /$ day) before the occurrence of acute dystonia.

Rapid increase of a dopaminergic antipsychotic may also be involved in the onset of dystonia ${ }^{7}$. A previous case of dystonia appearance related to rapid increase of risperidone dosage was reported, however with no PS manifestation ${ }^{8}$. Moreover other case reports of PS-induced risperidone have also been described ${ }^{9}$, nevertheless in the present case the patient had no history of putative risk factors described for PS.

Once the PS begins, the treatment remains empirical, which reflects the poor understanding of its underlying pathophysiology ${ }^{10}$. The first-line treatment for PS has been the reduction in dosage or discontinuation of antipsychotics, while the second-line treatment has been the introduction of an anticholinergic medication, as PS is a side effect caused by the central dopaminergic blockade?

In the follow-up of patients who presented PS with risperidone, the substitution to other atypical antipsychotics that does not present high affinity for dopaminergic $D_{2}$ receptors, as olanzapine, may provide an interesting alternative for their treatment, as occurred in the present case report ${ }^{9}$.

In summary, clinicians should be aware of rapid upward titration and high dosage of risperidone because these conditions may precipitate PS even in patients without risk factors for the development of such adverse effect. Once the patient presents PS, the treatment may include the reduction in dosage or discontinuation of the antipsychotic drug, associated to the introduction of an anticholinergic medication, and in the follow-up drugs with low affinity for dopaminergic $D_{2}$ receptors must be used.

\section{REFERENCES}

1. Harada KI. Pisa syndrome without neuroleptic exposure in a patient with Parkinson's disease: a case report. Mov Disord 2006;21:2264.

2. Cordeiro Q Jr, Elkis H. Pancreatitis and cholestatic hepatitis induced by risperidone. J Clin Psychopharmacol 2001;21:529-530.

3. Duggal HS, Sivamony S, Umapathy C. Pisa syndrome and atypical antipsychotics. Am J Psychiatry 2004;161:373.

4. Rota E, Bergesio G, Dettoni E, Demicheli CM. Pisa syndrome during aripiprazole treatment: a case report. Prog Neuropsychopharmacol Biol Psychiatry 2007;31:286-287.

5. Cossu G, Melis M, Melis G, et al. Reversible Pisa syndrome (pleurothotonus) due to the cholinesterase inhibitor galantamine: case report. Mov Disord 2004;19:1243-1244.

6. Marder SR, Meibach RC. Risperidone in the treatment of schizophrenia. Am J Psychiatry 1994;151:825-835.

7. van Harten PN, Hoek HW, Kahn RS. Acute dystonia induced by drug treatment. BMJ 1999;319:623-626.

8. Brody AL. Acute dystonia induced by rapid increase in risperidone dosage. J Clin Psychopharmacol 1996;16:461-462.

9. Nishimura K, Mikami Y, Tsuchibuchi S, Horikawa N. Pisa syndrome resolved after switching to olanzapine. J Neuropsychiatry Clin Neurosci 2007;19:202-203.

10. Suzuki T, Matsuzaka H: Drug-induced Pisa syndrome (pleurothotonus): epidemiology and management. CNS Drugs 2002;16:165-174. 